\title{
A Comparative Study of Intravenous Dexmedetomidine and Intravenous Clonidine for Prolongation of Lumbar Subarachnoid Block with Bupivacaine in Patients Undergoing Lower Abdominal Surgeries \\ Dr. P. Felin Paul ${ }^{1}$, Dr. Mahilamani $\mathrm{PP}^{2^{*}}$, Dr. Thavamani $\mathrm{A}^{3}$, Dr. Keerthana $\mathrm{P}^{4}$
}

\author{
${ }^{1}, \mathrm{~J}$ Junior resident, ${ }^{2}$ Professor, ${ }^{3} \mathrm{HOD}$ and Professor, Department of Anaesthesiology and Critical Care Medicine, Sree Mookambika \\ Institute of Medical Sciences, Kulasekharam, Tamil Nadu, India
}

DOI: $10.36347 /$ sjams.2021.v09i03.012

| Received: 17.02.2021 | Accepted: 01.03.2021 | Published: 05.03.2021

*Corresponding author: Dr. Mahilamani PP

\section{Abstract}

Background: Regional anaesthesia has several advantages over general anaesthesia, including spontaneous ventilation, retained upper airway reflexes, excellent analgesia, earlier recovery of bowel function, less need for systemic opioids, early post-operative ambulation etc. Clonidine and Dexmedetomidine are $\alpha 2$-adrenoreceptor agonists, who cause analgesia and sedation by acting on $\alpha 2$-receptors, present in the locus coeruleus and substantia gelatinosa of the spinal cord. Objectives: The present study was done to evaluate and compare the effects of intravenous Dexmedetomidine and intravenous Clonidine with placebo on the subarachnoid block duration, hemodynamic changes and sedation in patients undergoing elective lower abdominal surgeries under spinal anaesthesia with $0.5 \%$ hyperbaric bupivacaine. Methods: 75 patients who belonged to ASA physical status I \& II, posted for lower abdominal surgeries, were divided into three groups of 25 each. Group B received $10 \mathrm{ml}$ of physiological IV saline, Group C received 1 microgram $/ \mathrm{kg}$ of IV Clonidine, and Group D received $0.5 \mathrm{microgram} / \mathrm{kg}$ of IV Dexmedetomidine. After 10 minutes, a lumbar puncture was performed at L3, L4 spinal interspace, and $0.5 \%$ of hyperbaric bupivacaine $15 \mathrm{mg}$ was injected intrathecally. Results: The demographic profiles of the patients among the groups were comparable. There was no significant difference in the mean onset time of sensory analgesia at T10 dermatome and onset of motor blockade between the groups. Two-segment regression time of sensory block and the total duration of motor block was significantly prolonged in the dexmedetomidine group than the Clonidine group, which was significantly prolonged compared to the placebo group. A higher ratio of patients in Groups C and D required Atropine for management of bradycardia. The number of patients who had a fall in systolic blood pressure more than $20 \%$ of baseline value was not significant. The Ramsay sedation scores were significantly higher $(\mathrm{p}<0.05)$ in group D. Conclusion: Intravenous Dexmedetomidine and Clonidine prolong the duration of sensory block, motor block and post-operative analgesia but causes transient reversible bradycardia compared to placebo. Dexmedetomidine provides better sedation and longer duration of post-operative analgesia than Clonidine without further increasing the incidence of adverse effects.

Keywords: Intravenous, Clonidine, Dexmedetomidine, spinal anaesthesia.

Copyright ( 1 2021 The Author(s): This is an open-access article distributed under the terms of the Creative Commons Attribution 4.0 International License (CC BY-NC 4.0) which permits unrestricted use, distribution, and reproduction in any medium for non-commercial use provided the original author and source are credited.

\section{INTRODUCTION}

Regional anaesthesia has several advantages over general anaesthesia, including spontaneous ventilation, retained upper airway reflexes, early postoperative ambulation and low cost, etc. It is the preferred mode of anaesthesia whenever possible. But the disadvantages are the absence of anxiolysis and inadequacy in case of prolonged surgeries.

Several drugs like opioids, $\alpha 2$-agonists, neostigmine, and dexamethasone and magnesium sulphate have been used as additives with local anaesthetics to eliminate anxiety or to prolong the duration of anaesthesia and post-operative analgesia [1].

Clonidine and Dexmedetomidine are $\alpha 2$ adrenoreceptor agonists used intrathecally, cause sympatholysis, analgesia and sedation by action on $\alpha 2$ receptors in locus coeruleus and the substantia gelatinosa of the spinal cord [2]. Analgesic and sedative properties were found when these drugs were administered in the intrathecal, epidural or intravenous routes [3-5]

Citation: P. Felin Paul et al. A Comparative Study of Intravenous Dexmedetomidine and Intravenous Clonidine for 
The subarachnoid block is the preferred mode of anaesthesia for lower abdominal surgeries. This is due to the technical ease, rapidity of onset, and the block's reliability and completeness, but the duration of anaesthesia and analgesia is limited. This study was aimed to compare the efficacy and clinical profile of two $\alpha 2$-adrenergic agonists- Dexmedetomidine and Clonidine with the control group, when used as adjuvants to spinal anaesthesia, through the intravenous route in patients undergoing lower abdominal surgeries.

\section{Material ANd Methods}

This randomized double-blinded comparative study was done at Sree Mookambika Institute of Medical Sciences, Kulasekaram, from August 2019 to July 2020. After approval of Institutional Ethical Committee, 75 patients scheduled for lower abdominal surgeries who had given written informed consent, belonging to ASA-Physical status 1 to 2, between the age group of 20-60 were included in this study. Patients with uncontrolled hypertension, uncontrolled diabetes, cardiac arrhythmias, any neurological disorders or history of any spinal surgeries, coagulopathy, allergy to local Anaesthetics, Dexmedetomidine and Clonidine, and ASA-PS more than 2 were excluded from this study. The patients were randomly allocated to three study groups according to the list of random numbers.

A pre-anaesthetic evaluation was done. All patients were visited on the previous day of surgery, reassured, explained in detail about the anaesthetic technique and method of assessing sensory and motor blockade. Informed consent was taken and advised fasting regime. All patients were given T.RANTAC 150 mg+ T.ALPRAZOLAM $0.25 \mathrm{mg}$ on the previous night and T.RANTAC $150 \mathrm{mg}$ and T.METACLOPRAMIDE $10 \mathrm{mg} 2$ hours before the procedure. A multiparameter monitor was attached in the premedication room, and baseline parameters like HR, NIBP, Respiratory rate, and SPO2 were recorded and monitored throughout the perioperative period. An $18 \mathrm{G}$ intravenous cannula was secured, and RINGER LACTATE at a rate of $10 \mathrm{ml} / \mathrm{kg} / \mathrm{hr}$ was given over a period of 20 to 30 minutes before the procedure and continued intraoperatively.

Group $B(n=25)$ received $10 \mathrm{ml}$ of physiological saline IV, Group $\mathrm{C}(\mathrm{n}=25)$ received 1 microgram $/ \mathrm{kg}$ of Clonidine, I.V diluted to $10 \mathrm{ml}$ and Group $\mathrm{D}(\mathrm{n}=25)$ received 0.5 microgram $/ \mathrm{kg}$ of dexmedetomidine, I.V diluted to $10 \mathrm{ml}$. Following this, a lumbar puncture was performed under strict asepsis and lateral decubitus position after 10 minutes at L3, L4 spinal interspace and hyperbaric $0.5 \%$ Bupivacaine $15 \mathrm{mg}$ was injected intrathecally. Then the patient is made supine, and oxygen was supplemented at $3-4 \mathrm{~L} / \mathrm{min}$. The sensory block was assessed using ice packs in the mid-axillary plane bilaterally every 2 minutes from the injection till the sensory block reached the highest dermatomal level. The motor block was assessed at the time of the highest sensory level and was considered a maximum motor block. The highest sensory level was defined as the same block level that persisted for four consecutive tests. Motor block was assessed with Modified Bromage Scale (0-able to move hip, knee and ankle, 1unable to move hip but able to move knee and ankle, 2unable to move hip and knee but able to move the ankle, 3-unable to move hip, knee and ankle.) Duration of motor block was considered as the time when the modified Bromage scale returns to 0 . Highest dermatomal level of the blockade, time taken to reach the highest level, motor block at the highest sensory level, time to two-segment regressions, and duration of motor blockade were recorded.

Modified Ramsay Sedation Score was used for intraoperative sedation. (1=agitated, 2=cooperative, $3=$ responds to verbal commands, $4=$ brisk response to gabellar tap, 5=sluggish response to gabellar tap, $6=$ no response to gabellar tap). The systolic and diastolic blood pressure, heart rate, oxygen saturation and respiratory rate were recorded every 3 minutes in the first 30 minutes and every 5 minutes throughout the surgery. $\mathrm{SBP} \leq 90 \mathrm{~mm}$ of $\mathrm{Hg}$ or $30 \%$ decrease in baseline and heart rate less than 50 per minute were treated with Inj.EPHEDRINE $6 \mathrm{mg}$ intravenously and Inj.ATROPINE $0.6 \mathrm{mg}$ Intravenously, respectively. Adverse effects like hypotension, bradycardia, respiratory depression, shivering and pruritus were recorded.

The statistical analysis was done using SPSS trial version 18 . The student's t-test was used to analyze the age, height, weight, duration of surgery, baseline and lowest BP, Recovery time and Sensory and Motor blockade, intergroup differences of peak sensory level and maximum motor block score were tested with Mann-Whitney U Test.

Data were expressed as Mean (SD), Median (Interquartile range [range] or number as appropriate and $\mathrm{p}$-value $<0.05$ were taken as statistically significant.

\section{RESULT}

The demography of the three groups was comparable with respect to age, height, weight, ASAPS class and mean duration of surgery (Table 1). 
P. Felin Paul et al; Sch J App Med Sci, Mar, 2021; 9(3): 360-363

Table-1: Demographic profile (mean \pm SD)

\begin{tabular}{|l|l|l|l|l|}
\hline S. No & PARAMETERS & GROUP B & GROUP C & GROUP D \\
\hline 1 & Age in years & $37.10 \pm 14.09$ & $37.42 \pm 11.84$ & $36.52 \pm 11.12$ \\
\hline 2 & Weight $(\mathrm{kg})$ & $58.82 \pm 7.91$ & $62.82 \pm 6.99$ & $61.32 \pm 7.78$ \\
\hline 3 & Height $(\mathrm{cm})$ & $1.59 \pm 0.05$ & $1.59 \pm 0.05$ & $1.59 \pm 0.06$ \\
\hline 4 & Duration of the procedure (minutes) & $62 \pm 16.7$ & $64 \pm 12.3$ & $64 \pm 14.4$ \\
\hline 5 & ASA PS $1 / 2$ & $12 / 13$ & $15 / 10$ & $14 / 11$ \\
\hline
\end{tabular}

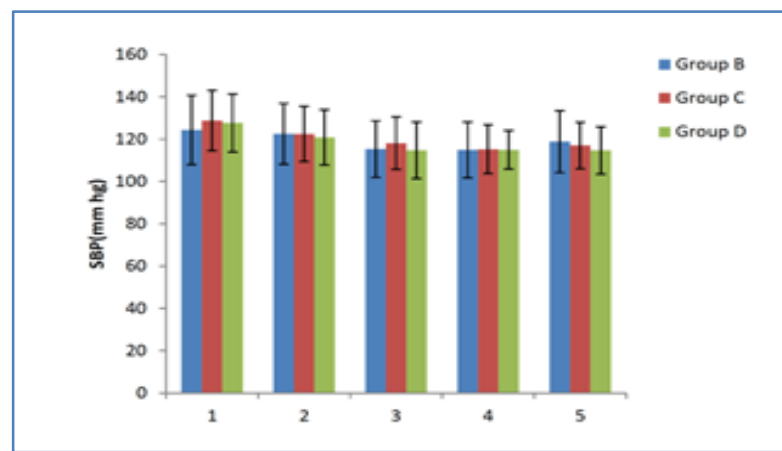

Graph-1: Comparison of SBP $(\mathrm{mm} \mathrm{Hg})$ in three groups

1-Pre-operative hemodynamic, 2Haemodynamic following premedication, 3Haemodynamic following SAB, 4- Intraoperative hemodynamic, 5- Post-operative Haemodynamic

There is no significant difference in SBP among the three groups.

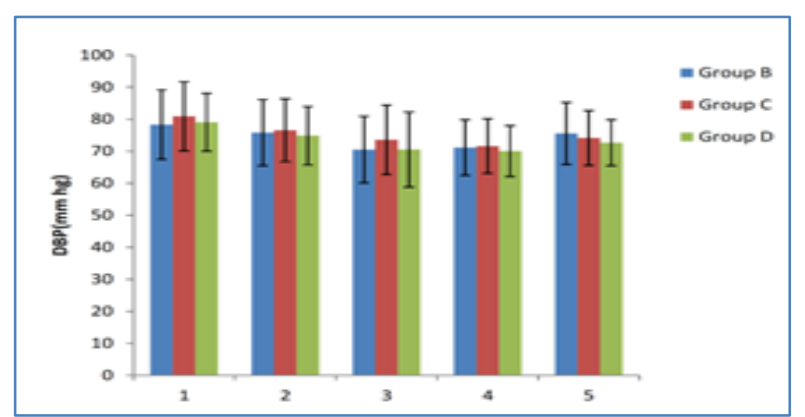

Graph-2: Comparison of DBP $(\mathrm{mm} \mathrm{Hg})$ in three groups
1-Pre-operative hemodynamic, 2Haemodynamic following premedication, 3Haemodynamic following $\mathrm{SAB}, 4-$ Intraoperative hemodynamic, 5- Post-operative Haemodynamic.

There is no significant difference in DBP among the three groups.

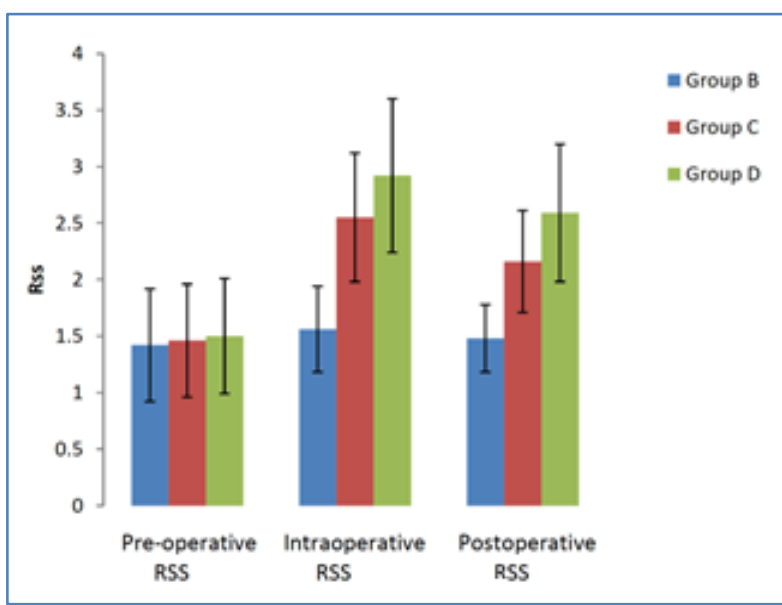

Grap-3: Comparison of Ramsay Sedation Score in three groups

Intraoperative and Postoperative mean sedation scores are significantly higher in Groups $\mathrm{C}$ and $\mathrm{D}$ when compared to Group B $(\mathrm{P}<0.001)$. Intraoperative and Postoperative mean sedation scores are significantly higher in Groups D when compared to Group C $(\mathrm{P}<0.001)$

Table-2: Side effects

\begin{tabular}{|l|l|l|l|l|}
\hline S. No & Side effects & Group B & Group C & Group D \\
\hline 1 & Bradycardia & 1 & $7 *$ & $8^{*}$ \\
\hline 2 & Hypotension & 2 & 4 & 4 \\
\hline 3 & Pruritus & 0 & 0 & 0 \\
\hline 4 & Respiratory depression & 0 & 0 & 0 \\
\hline 5 & Shivering & 3 & 1 & 1 \\
\hline 6 & Nausea and vomiting & 2 & 1 & 1 \\
\hline \multicolumn{4}{|c|}{$*$ p-value $(<0.05)$} \\
\hline
\end{tabular}

\section{DISCUSSION}

Dexmedetomidine and Clonidine have been used as adjuvants to local anaesthetics by intrathecal, epidural, caudal, intravenous routes, and peripheral nerve blocks. Dexmedetomidine is a highly selective $\alpha 2$-adrenoreceptor agonist with $\alpha 2: \alpha 1$ binding ratio of 1620:1 compared to 220:1 for Clonidine [2].
The demographic profiles of the patients among the groups were comparable with regards to age, weight and height. There was no significant difference in the mean onset time of sensory analgesia at T10 dermatome and onset of motor blockade between the groups. Similar results were seen in the study by Gupta et al. [6]. In the present study, two-segment regression 
time of sensory block and time to regression to Bromage 1(motor block) were significantly prolonged in the dexmedetomidine group than Clonidine and placebo groups $(\mathrm{P}<0.001)$ This was similar to the study by Kapdi et al. [7] which showed a significant increase in the duration of the motor block with Dexmedetomidine.

Kim et al. [8] found that the ED95 of a single dose of Dexmedetomidine to induce light sedation was $0.38 \mathrm{ug} / \mathrm{kg}$. Significant prolongation of anaesthetic effect was observed with dose as low as $0.5 \mathrm{ug} / \mathrm{kg}$ administered as isolated boluses in the absence of maintenance infusion. Thus, a dose of $0.5 \mathrm{ug} / \mathrm{kg}$ was selected in our study. Previous studies have elucidated a dose of Clonidine, which is 1.5-2 times higher than the dose of Dexmedetomidine. Based on the observation of prior studies dose of $1.0 \mathrm{ug} / \mathrm{kg}$ of Clonidine was selected in our study. As rapid administration of Dexmedetomidine might produce tachycardia, bradycardia and hypertension, we administered the drug over 10 minutes in our study.

F.N.Kaya et al. [9] showed that the sedation produced by Dexmedetomidine differs from other sedatives, as patients may be easily aroused and remain co-operative. In our study, the mean intraoperative and post-operative sedation scores were significantly higher in Group D when compared to Groups B and C (P-value $<0.001)$.

Abdullah et al. [10] concluded that use of Dexmedetomidine was associated with a three-fold increase in transient reversible bradycardia requiring Atropine. A higher proportion of patients in Groups C and $\mathrm{D}$ required Atropine for management for bradycardia $(\mathrm{P}<0.001)$. The number of patients who had a fall in Systolic Blood Pressure more than $20 \%$ of baseline value was not significant.

Niu et al. [11] had observed that the use of Dexmedetomidine, including intravenous and intrathecal, could statistically significantly prolong the duration of sensory and motor block; hence we chose the intravenous route in this study.

It was found that side-effects like shivering and nausea vomiting were lower in group $\mathrm{C}$ and $\mathrm{D}$. We infer from these studies that Clonidine and Dexmedetomidine prolonged the duration of spinal block and post-operative analgesia.

\section{Conclusion}

Premedication with intravenous Dexmedetomidine or Clonidine significantly prolongs sensory and motor block duration and provides intra- operative sedation and post-operative analgesia. Both Dexmedetomidine and Clonidine cause hypotension and significant bradycardia, which are transient and easily treatable. Dexmedetomidine provides a longer duration of sensory block, motor block and sedation and postoperative analgesia than Clonidine without further increasing the incidence of adverse effects.

\section{LIMITATIONS}

The number of patients enrolled in this study was less. We enrolled only 25 patients in each study group.

\section{REFERENCE}

1. Christiansson L. Update on adjuvants in regional anaesthesia. Period. Biol. 2009; 111: 161-170.

2. Grewal A. Dexmedetomidine: New avenues. J. Anaesthesiol. Clin. Pharmacol. 2011; 27: 297-302.

3. Dobrydnjov I and Samarütel J. Enhancement of intrathecal lidocaine by addition of local and systemic Clonidine. Actaanaesthesiologica Scandinavica. 1999; 43.

4. Bajwa SJS. Dexmedetomidine and Clonidine in epidural anaesthesia: A comparative evaluation. Indian J. Anaesth. 2011; 55: 116-121.

5. Whizar-lugo V. Intravenous Dexmedetomidine vs. Intravenous Clonidine to prolong Bupivacaine Spinal Anesthesia. A Double Blind Study. 2019: 143-146.

6. Gupta K, Tiwari V, Gupta PK, Pandey MN and Agarwal S., Prolongation of subarachnoid block by intravenous Dexmedetomidine for below umbilical surgical procedures: A prospective control study. Anesth. Essays Res. 2014; 8: 175-178.

7. Kapdi Manisha. Intravenous Dexmedetomidine Prolongs Motor and Sensory Effect of Spinal Anaesthesia Medical Science. Int. J. Sci. Res. 2014; 3: 336-338.

8. Kim JE, Kim NY, Lee HS and Kil, HK. Effects of intrathecal Dexmedetomidine on low-dose bupivacaine spinal anesthesia in elderly patients undergoing transurethral prostatectomy. Biol. Pharm. Bull. 2013; 36: 959-65.

9. Kaya FN. Intravenous Dexmedetomidine, but not midazolam, prolongs bupivacaine spinal anesthesia. Can. J. Anesth. 2010; 57: 39-45.

10. Abdallah FW, Abrishami A and Brull R. The facilitatory effects of intravenous Dexmedetomidine on the duration of spinal anesthesia: A systematic review and meta-analysis. Anesthesia and Analgesia. 2013; 117: 271-278.

11. Niu XY. Effects of intravenous and intrathecal Dexmedetomidine in spinal anesthesia: A metaanalysis. CNS Neurosci. Ther. 2013; 19: 897-904. 